\title{
Ready, set, go
}

\author{
The lead up to the Rio Olympics has been littered with concerns over Zika virus and polluted waterways rich \\ in pathogenic viruses and potentially drug-resistant bacteria. Despite these fears, appropriate precautions \\ should ensure the games are celebrated for their sporting triumphs, not condemned for public health failures.
}

In a few days' time the eyes of the world will turn to Brazil and the 2016 Olympics, hosted predominantly in Rio de Janeiro. Constituting by far the largest global event in the sporting calendar, the games will comprise over 10,000 athletes taking part in 306 events, spread across 42 disciplines. In addition to the competitors, their coaches and support staff, the influx of foreign spectators is expected to mean that around half a million additional people will step out on to Rio's streets during the games. Any gathering on such a scale brings with it potential risks for transmission of infectious diseases, yet careful planning to ensure appropriate public health systems are put in place has, so far, meant that at previous Olympics the absolute risk from infectious diseases remained small. What, then, for Rio 2016?

The run up to the games has been dominated by the Zika epidemic and fears that the increased number of international visitors could accelerate the spread of the virus. Indeed a small number of competitors, mostly male golfers, have withdrawn from competition owing to fears of infection and transmitting the virus to pregnant partners. However, these fears are likely to prove unfounded. The number of Zika cases reported in Rio has dropped substantially in recent months and is expected to continue to decline to almost nothing owing to the dry winter season during which the games are being held. In Rio, cases of infection with dengue virus, which is also transmitted by the Aedes mosquito vector, normally peak during the rainy season in March and April and then drop to almost none during the cooler and drier winter months. Organizers of the games are not relying solely on climatic conditions to minimize the risk from Zika though, with daily inspections to remove stagnant pools of water in which remaining mosquitoes might breed. The emergency committee regarding microcephaly, other neurological disorders and Zika virus, convened by the Director General of the WHO, recently echoed this assessment. They concluded that there is very low risk of further international spread of Zika virus owing to the Olympic and Paralympic games. Meeting for the third time, the committee concurred with the growing scientific consensus supporting Zika virus as a cause of microcephaly and Guillain-Barré syndrome. They also noted that the individual risk for infection in areas of transmission are the same irrespective of whether a mass gathering is happening, and that good public health protection measures can help to minimize this risk. Despite calls to postpone or cancel the games from some quarters, Zika should not pose a substantial risk to those taking part. It is regretful that some individuals won't be competing for their countries in this year's games, especially since the opportunity to do so does not come around many times in a sportsperson's career.

Another area of microbiological concern at the games relates to the poor quality of many of the waterways and beaches that will play host to events including openwater swimming, triathlon, sailing and wind-surfing. Unsafe levels of enteroviruses, rotaviruses, adenoviruses and faecal bacteria (including antibiotic-resistant strains) have been found in the water at Rio's water sport venues during tests over the past three years. The poor quality of water and risk of infection will clearly be of concern to athletes competing in these waters. As a result steps have been taken to mitigate the conditions. Many athletes will be arriving in Rio close to the start of competition to limit exposure and risk of developing an illness. The US Olympic rowing team are to wear garments with an 'antimicrobial finish' that they hope will provide an additional degree of protection. However, such suits leave much of the skin on limbs, as well as the head, exposed, leaving many routes for infection open. The impregnated antimicrobial will also not be effective against viral contaminants in the water. Fortunately, one of the major factors affecting whether these water-borne pathogens will be able to infect and cause illness is the immune status of the individual involved. In this regard, the Olympians risking exposure in Rio's contaminated waters will likely have an advantage, being at the peak of physical fitness and health. Careful washing of exposed areas of skin and equipment on leaving the water will hopefully be sufficient to minimize risk of illness and the impact on open waterbased competitions. Notably, as far as this journal is aware, no competitor taking part in a water sport event has yet withdrawn from the games, despite the knowledge of likely exposure. It may be that leading up to the games, Zika virus has received disproportionate attention during coverage, and its relative low risk could have been better communicated by the global media.

\section{Despite calls to postpone or cancel the games from some quarters, Zika should not pose a substantial risk to those taking part.}

To coincide with the London Olympics in 2012, our sister title, Nature Reviews Microbiology invited researchers from different parts of the field to contribute an event to an article entitled 'The Microbial Olympics' (M. Youle et al., Nature Rev. Microbiol. 10, 583-588; 2012). The editors assigned the events and asked them to conduct a thought-experiment in which they designed the event rules, selected competitors from across the microbial world and assigned them gold, silver and bronze medals, explaining the reasons for each placing. To this end, there were events including the sprint, the javelin and the pathogen relay. Some researchers went even further, actually putting together a video in which bacterial competitors competed in the $100 \mu \mathrm{m}$ freestyle swimming race. The overall result was educational and humorous (occasionally cringe-worthily so, especially the use of good/bad puns), but it was also different in intent and result from the usual fare published by serious academic journals. Well, just as the real-world Olympic Games changes venue every four years, the same is true in the microbial world! In this issue of Nature Microbiology, we are pleased to welcome you to the Microbial Olympics 2016 (article no. 16122). We hope that you will find it equally interesting and amusing as the first games, puns and all. 